\title{
Alcance e Limites das Teorias da Modernização
}

Lia Pinheiro Machado*

1. Algumas Conseqüências da Perspectiva Teórica e dos Pressupostos das Teorias da Modernização para a Compreensão do Subdesenvolvimento. 2. Incorporação Critica das Teorias da Modernização numa Compreensão Alternativa do Subdesenvolvimento. 3. Conclusão.

O objetivo do presente estudo é uma discussão sôbre as consequências do ponto de partida teórico e da tipologia empregada pelas teorias da modernização na compreensão do fenômeno do subdesenvolvimento.

Tentaremos perceber não só as contribuições mas contestar crìticamente determinadas afirmações explícitas e implícitas.

Por que seria importante uma compreensão crítica dessas teorias? Essas teorias concebem determinadas características psicossociais como causas necessárias e, em alguns momentos, suficientes para o desenvolvimento econômico. Esse enfoque pode ser extremamente prejudicial ao levar teóricos, planejadores, governantes, administradores a atribuir $o$ atraso econômico-social de alguma região ou de alguma instituição e organização às características psicossociais dos seus membrosparticipantes.

Ao observarem o atraso de uma região agrícola no emprêgo de tecnologia avançada, o cultivo de milho e de mandioca para

* Socióloga da Fundação Educacional do Estado do Paraná.

R. Adm. Emp., Rio de Janeiro, 10(2): 169-192, jul./set. 1970 
subsistência ao invés de produção para o mercado, a existência de pequenas fábricas de fundo de quintal ao invés de grandes unidades, ou, ainda, a utilização de máquinas obsoletas ao invés das mais recentes inovações, atribuiriam tal situação às atitudes tradicionais da população incapaz de mudar.

Para as teorias da modernização, atitudes contrárias à mudança são características inerentes ao tipo de sociedade atrasada econômicamente. $O$ que significa tal colocação? Significa que, se tais atitudes são consideradas inerentes, deixarão de ser explicadas. $O$ perigo dessa colocação está em desviar os estudiosos de um outro modo de formular o problema: as atitudes podem ser consequientes de uma situação desvantajosa dêsse grupo face a outros.

A produção para o mercado pode exigir de um agricultor, por exemplo, um instrumental de trabalho que êle não pode adquirir, exigir margem de risco muito grande que não pode suportar, oferecer margem pequena de lucro, desde que perca grande parte para o intermediário revendedor, ou para o industrial comprador pela dificuldade de impor-lhes condições. Em relação à utilização de equipamento técnico já superado, em vez de significar um atraso sem razão, pode representar o meio mais acertado para atender a um mercado restrito que não comportaria a produção em larga escala dos equipamentos mais avançados tècnicamente. Anàlogamente, um pequeno empresário só pode se manter desde que não atenda apenas à clientela residual de uma grande emprêsa, e não se aventure a expandir sua produção. Inúmeras outras situações poderiam ser as causas das atitudes e comportamentos adequados e não consequências de atitudes tradicionais atrasadas.

Resta, ainda, uma pergunta extremamente importante: tais situações são casuais ou consequiências de características estruturais dessas sociedades? Se conseguirmos localizar as causas da configuração dessas situações, estaremos mais próximos de uma compreensão do fenômeno do subdesenvolvimento.

Esboçado preliminarmente, como entendemos, o interêsse de uma compreensão crítica das teorias da modernização, destacaremos, para efeito de análise, determinados conceitos e afir- 
mações das teorias da modernização, e enfatizaremos as consequiências para a compreensão do subdesenvolvimento. Finalmenmente, optaremos por uma alternativa teórica para a explicação do subdesenvolvimento, ora rejeitando, ora incorporando criticamente o que é afirmado pelas teorias da modernização.

\section{Algumas Conseqüências da Perspectiva Teórica e dos Pres- supostos das Teorias da Modernização para a Compreensão do Subdesenvolvimento.}

\subsection{O SUBDESENVOLVIMENTO SERIA O ESTADO ORIGINAL, ATRA- SADO E TRADICIONAL DA ORGANIZAÇÃO SOCIETARIA.}

As teorias da modernização concebem a existência de apenas dois tipos fundamentais de sociedade humana: a sociedade tradicional e a sociedade moderna.

Cada um dêsses tipos de sociedade se caracteriza por um modo de organização social, econômica e política que apresentam um traço comum entre si.

O traço característico comum à sociedade tradicional é a estabilidade ao longo do tempo e a pequena variabilidade de situações diferentes entre os agentes sociais. Os agentes sociais realizam um número restrito de atividades econômicas de baixa produtividade. Ocupam posições estabelecidas e transmitidas hereditàriamente. A mobilidade, portanto, é pequena, a estrutura social rígida e os costumes repetitivos. A autoridade política é exercida hereditàriamente por elementos de algumas famílias.

O traço comum aos diferentes níveis de organização na sociedade moderna é a mudança contínua e a variabilidade de situações entre os agentes sociais. Os agentes sociais realizam atividades econômicas de alta produtividade, e exercem funçőes diferenciadas numa complexa divisão de trabalho. De acôrdo com tais funções, ocupam posições e status social. Como é possível mudar a função exercida, a mobilidade é grande, e a estrutura social flexível. A flexibilidade das posiçóes sociais significa igualdade entre os indivíduos e permite uma organização política de participação ampla. 
Se a estabilidade é o traço comum das organizações economica, política e social da sociedade tradicional e a mudança na sociedade moderna, as teorias da modernização não apresentam base teórica que defina a interrelação entre as instâncias política, econômica e social. Ao conceituarem os dois tipos de sociedade, apenas afirmam que há interrelação entre as variáveis, sem definir o modo de interrelação.

Germani, por exemplo, arrola um conjunto de características da sociedade tradicional comparadas à sociedade moderna em todos os níveis, sem nenhuma preocupação em definir se alguma característica teria poder explicativo sôbre as outras. ${ }^{1}$

O não estabelecer teòricamente o modo de interrelação entre as instâncias política, econômica e social tem, como consequiência, dar autonomia a cada uma das instâncias. Além disso, abre a possibilidade tentadora de se procurar a explicação de características sociais nas características econômicas e vice-versa, estabelecendo um círculo vicioso e tornando a causalidade extremamente ambígua. Veremos que isso, de fato, ocorre quando analisarmos a que fatôres as teorias de modernização atribuem. a causalidade do desenvolvimento.

Os dois tipos de sociedade são concebidos como estados em que a sociedade tradicional é considerada o estado inicial de uma evolução social cujo ponto de chegada é a sociedade moderna. Germani e Lerner localizam a configuração de sociedades modernas, exclusivamente, no mundo moderno, a partir do progresso tecnológico iniciado com a Revolução Industrial do século XVIII na Inglaterra. Tôdas as sociedades das épocas anteriores e as do mundo contemporâneo, que ainda não se tecnificaram, são tradicionais. Hagen e Mcclelland concebem sociedade tradicional e moderna como estados, essencialmente, de crescimento econômico que ocorreram, ocorrem e podem ocorrer nas diferentes épocas históricas. Definidos como estados de evolução social, essa tipologia não está vinculada a um momento histórico e à sua singularidade. ${ }^{2}$

1 Germani, Gino. Politica y Sociedad en una Epoca de Transación, Buenos Aires, Editorial Paidos, 1962.

2 HAGEN, E. E. On the Theory of Social Change, Homewood, Ill., The Donsey Press, 1962. Mcclelland, D.C., The Achieving Society. Princeton, Nova Iorque, D. Van Nostrand Co., Inc., 1961. 
Essa tipologia pressupõe um mundo formado de várias sociedades que, independentemente umas das outras, configuram diferentes estados tradicional ou moderno no tempo e no espaço. Ao ser utilizada essa tipologia no mundo atual, o pressuposto também será o mesmo: o mundo atual é constituído de unidades básicas independentes, os estados-nações. Face às disparidades de desenvolvimento econômico constatadas entre os estados-nações, se a tipologia em questão fôr utilizada, a explicação do atraso e da vanguarda de algumas nações no processo de desenvolvimento será buscada nas próprias características internas de cada nação.

Os tipos de sociedade tradicional e moderna são estados de sociedades consideradas como unidades independentes, e cada uma plenamente indentificável face às outras, podendo ser explicada sem referência às relações entre elas. $O$ emprêgo dessa tipologia tem como conseqüência que a configuração das relações internacionais nas diferentes épocas e momentos históricos deixa de ser considerada como um elemento constitutivo do desenvolvimento ou do não-desenvolvimento de algumas nações.

A concepção da existência de apenas dois tipos de sociedade significa que o sistema econômico capitalista e socialista e suas diferentes modalidades em que se inserem as várias naçóes também não será levado em conta na explicação da disparidade econômico-social. Se o modo de constituição e expansão do capitalismo inicial, ou a sua estrutura atual, ou o modo de constituição e expansão do socialismo, tiveram ou têm papel explicativo para o desenvolvimento e para o subdesenvolvimento, de qualquer modo não serão considerados, pois, teòricamente, já não são critérios relevantes de diferenciações de sociedades.

Há, ainda, outro pressuposto teórico que limita mais o campo de elementos que poderiam ser concebidos como explicativos do subdesenvolvimento. O pressuposto teórico é que a sociedade tradicional é uma situação de origem, o ponto inicial da evolução social. Uma organização societária em estado inicial, primitivo, não parece pedir explicações, e ainda permanece porque não atingiu determinadas condições para mudar. Os téricos da modernização não se preocupam, nem podem buscar uma expli- 
cação para um estado que definem como o ponto inicial da organização das sociedades.

Concebida teòricamente a evolução social como a passagem de um estado tradicional para um moderno, a preocupação central dos teóricos da modernização é explicar como se dá a passagem de um estado para outro e como se poderá dar.

O processo de modernização é a transformação de uma sociedade do estado tradicional para o moderno. O conceito de modernização, tal como é empregado nesse contexto teórico, é sinônimo do conceito de desenvolvimento no sentido impreciso e vago de supor que a introdução do progresso técnico resulta num crescimento da renda real que beneficia, igualmente, tôdas as camadas da população.

Desde que o estado de modernidade em comparação com o de tradicionalidade implica numa diferenciação em tôdas as dimensões, o conceito de modernização abrange as dimensões econômicas, políticas e psicossócioculturais.

Modernização significa mudanças econômicas, políticas e sociais que podem ser definidas antes mesmo que ocorram numa sociedade, pois a modernização já ocorreu nas atuais sociedades desenvolvidas ou modernas. Nesses mesmos moldes é prevista para as atuais sociedades subdesenvolvidas, atrasadas ou tradicionais ou aquelas em transição. A modernização assim entendida pressupõe a identificação do processo do desenvolvimento que se iniciou no século XVIII e o desenvolvimento tardio atual.

Como se admite teòricamente que a evolução da tradicionalidade para a modernidade ocorre em unidades sociais independentemente das relaçóes entre si, ou do sistema econômico, ao mesmo tempo, está-se admitindo teỏricamente que os obstáculos à modernização estariam exclusivamente nas suas características internas tradicionais.

Se as características tradicionais forem superáveis, a modernização ocorrerá. Teỏricamente não se admitem outros obstáculos.

Faremos um resumo da exposição acima para enfatizarmos as implicações na compreensão do subdesenvolvimento da perspectiva teórica e da tipologia das teorias da modernização. 
a) Sociedade tradicional e moderna são constituídas, cada uma, por um conjunto de variáveis sociais, políticas e econômicas, cujo inter-relacionamento não é definido.

b) Os estados-naçóes são independentes, e as relaçóes internacionais não são relevantes para caracterizar o desenvolvimento e o subdesenvolvimento.

c) O subdesenvolvimento ou estado de tradicionalidade é um estado de origem que não admite explicação.

d) O conceito de modernizaçãa pressupõe transformações na organização econômica, social e política cujos efeitos atingem tôdas as camadas da população.

e) A modernização é um processo sempre no mesmo sentido, independente de tempo e espaço.

f) Desde que os valôres tradicionais sejam superados, ocorrerá a evolução social modernizante.

Passamos agora a analisar como as teorias da modernização atribuem a determinados elementos da realidade a qualidade de fatôres causais do desenvolvimento e do subdesenvolvimento.

\subsection{CARACTERISTICAS PSICOSSOCIAIS SERIAM RESPONSAVEIS PELO DESENVOLVIMENTO E SUBDESENVOLVIMENTO}

Os teóricos da modernização estão bàsicamente preocupados em explicar a disparidade econômico-social dos estados-nações no mundo atual.

Para explicá-la, vão determinar os fatôres que permitiram o desenvolvimento. Presentes numa sociedade, a modernização ocorre, inexistentes, não há desenvolvimento.

Os dois estados típicos de sociedade apresentam um conjunto totalmente diferenciado na organização econômica, política e social. Os fatôres que, presentes numa sociedade, são responsáveis pelo desenvolvimento, só podem ser características já inseridas na definição do tipo-estado de sociedade.

Para poder determinar os fatôres causais da modernização dentro da própria sociedade moderna, o meio utilizado foi isolar a dimensão social da econômica e tomar uma como causa, outra como efeito. 
Os teóricos da modernização colocam como seu objetivo explicar porque algumas sociedades alcançam sucesso nas atividades econômicas, e desenvolvem técnicas altamente produtivas. Nesse momento o crescimento econômico assume importância dominante, é a característica que distingue a sociedade tradicional da moderna. Não mais o estado da modernidade mas, sim, o fenômeno a ser explicado é o crescimento econômico resultante do progresso científico e tecnológico. Aqui o crescimento económico parece bastar para definir sociedade moderna.

Ao isolar-se a dimensão econômica da social, está-se-lhes dando autonomia.

A formulação de que o desenvolvimento e o subdesenvolvimento podem ser explicados, isolando-se a dimensão econômica da social, é bem clara em Mcclelland. ${ }^{3} \mathrm{O}$ autor se propõe a compreender porque, se nas sociedades desenvolvidas funciona um modêlo e mecanismos de crescimento econômico de uma produção tal que permite continuamente aumento do poder de consumo da população e do poder de poupança para novos investimentos, êsse modêlo não funciona nas sociedades subdesenvolvidas. A resposta é encontrada na inexistência da estrutura de caráter e motivacional que levaria a população a consumir, poupar e investir apropriadamente para o desenvolvimento. Vejamos sua formulação através de suas próprias palavras:

... "to an economist higher real income means higher saving which permits higher investment in capital improvements which increases income and so on in a beneficient cycle".4

"Classical economic theorist could be satisfied with such a model because they could assume that the people they knew in the countries of the West would act, on the average, in the ways required as opportunities presented themselves. But the precise problem of most underdeveloped countries is that they do not have the character structure, especially the motivational structure, which would lead them to act in the ways required.

3 MCCLeLland, D.C., op. cit., 1962.

4 Veja-se Mcclelland. The Achieving Society. Princeton. Nova Jersei, D. Van Nostrand Company, Ltd., 1961, p. 427. 
The model is like a combustion engine without the gas to make it go".

Mcclelland define a atitude responsável pelo crescimento econômico como a "motivação para o desempenho", isto é, o desejo de se realizar pessoalmente através de uma atividade que atinja padróes de excelência. ${ }^{6}$ Hagen considera criatividade isto $e$, abertura à experiência, imaginação criadora, energia, etc., responsável pela inovação que, ao se dar no campo tecnológico, resulta em crescimento econômico. ${ }^{7}$ Lerner considera a personalidade empática capaz de se imaginar e se colocar na situação do outro, de operar num mundo em mudança, o elemento dinâmico constituinte de crescimento. ${ }^{8}$

Independente das diferenciações na caracterização das atitudes responsáveis pelo crescimento econômico, os autores são unânimes em considerar tais atitudes ou características psicossociais, responsáveis pelos comportamentos efetivos necessários às atividades altamente produtivas. São variáveis necessárias: sem elas, não há desenvolvimento. São fatôres antecedentes causais.

Tomadas como elementos causais de determinadas condiçóes e modo de vida, as características psicossociais passam a não admitir explicação. Motivaçóes, atitudes e comportamentos só podem adquirir tal autonomia numa perspectiva teórica que fragmenta o processo de interação social. Nessa perspectiva, a interação é concebida e explicada numa dimensão puramente social, prescindindo de referência ao modo de organização econômica e política. Uma teoria que se pretenda explicativa da realidade social concreta năo poderia supor que os homens se relacionassem socialmente, criassem seu valôres, atitudes e comportamentos, independentemente do modo de se relacionarem para a produção econômica e das relações de poder vigentes.

As características psicossociais responsáveis pelo desenvolvimento ou modernização são típicas da sociedade moderna. Aqui

$5 \quad$ Idem, p. 427.

- Mcclelland, David C., op. cit., 1962.

7 Hagen, E. E., op. cit., 1961.

8 LeRner, Daniel, The Passing of Traditional Society, Nova Iorque, The Free Press, 1958. 
o inter-relacionamento das variáveis sociais e economicas é estabelecido claramente: as variáveis sociais são explicativas e as variâveis econômicas dependentes.

A dimensão social assume uma autonomia e um alto poder explicativo. Explicam as condições econômicas e passam a não admitir explicações. As características sociais simplesmente são o que são. Se as características psicossociais não são explicadas, elas aparecem como as variáveis mais importantes na determinação do tipo de sociedade.

Se a motivação para o desempenho, a criatividade tecnológica, a capacidade de empatia são responsáveis pelo desenvolvimento, as atitudes repetitivas, conformativas à situação, contrárias e incapazes de mudança, são responsáveis pelo não-desenvolvimento.

Essas atitudes repetitivas e conformativas também não admitem explicação. São típicas da sociedade tradicional que é o estado inicial ainda atrasado da evolução humana.

Já que as características psicossociais não encontram explicação nas condições econômicas e políticas, e uma vez observado empiricamente que as açōes e as atividades diferem nas nações desenvolvidas e subdesenvolvidas, deduziu-se que a divergência dos valôres que moviam os agentes em umas e outras sociedades era a causa das diferentes condiçōes de desenvolvimento. Os pontos de partida para diferenciar as atitudes dos agentes sociais em nações desenvolvidas e subdesenvolvidas partiram do senso comum. No âmbito das teorias da modernização, é relevante a observação de que, numa e noutra sociedade, agentes sociais trabalham e encaram o trabalho de forma diferente, uns se preocupam mais com o futuro, outros vêem passivamente o presente. No senso comum, chegou-se à imagem, em têrmos anedoticos, de que o europeu é um trabalhador, o brasileiro é um preguiçoso e indolente por natureza, etc.

Propiciaram a difusão nas ciências sociais de rótulos para as populações das sociedades atrasadas. Tais rótulos funcionam como caracterização a priori para inúmeros cientistas. Num estudo para entender o crescimento econômico atrasado no Brasil, Rosen, por exemplo, apresenta como hipótese que a explicação 
parcial dessa situação seria encontrada na pouca motivação para o desempenho e em poucos valôres sociais relacionados ao desempenho entre os brasileiros. Rosen, no entanto, considera impossível provar a causalidade das motivações sociais em relação ao desenvolvimento. Prova apenas que há correlação entre as duas variáveis. $O$ problema, no entanto, de explicar porque aparecem ou não determinadas atitudes, permanece. Permanece também a possibilidade de se arrolarem características, talvez peculiares a uma sociedade, mas que não sejam significativas para o desenvolvimento. Permanece a impossibilidade de se provar que atitudes descritas como tradicionais sejam conseqüência de um suposto estado primitivo anterior.

Dada a ênfase às características psicossociais como elementos causativos do desenvolvimento, o conceito de modernização se ligou estreitamente à dimensão social, isto é, modernização de atitudes, hábitos e comportamentos. Desvinculando-se as atitudes modernas da qualidade de condições necessárias e suficientes do desenvolvimento e as atitudes tradicionais de consequencias de um estado supostamente inicial da evolução social, o conceito de modernização seria extremamente útil. $O$ conceito de modernização seria aplicado ao nível da consciência dos agentes sociais. Com ele se poderia perceber características peculiares de diferentes processos de desenvolvimento: as aspirações dos agentes sociais, suas concepções do mundo, da sociedade, modos de se situar na vida urbana ou rural, de perceber a existência de outras sociedades mais ou menos desenvolvidas, etc. Seria extremamente útil e capaz de fazer perceber características peculiares de diferentes processos de desenvolvimento.

O modo de os agentes se situarem frente a uma organização econômico-social mais ou menos desenvolvida, não pode ser considerado isoladamente das condições e situações em que vivem, nem das possibilidades oferecidas.

Mesmo os teóricos da modernização não levam às ũltimas conseqüências o que afirmam em relação aos fatôres causativos do desenvolvimento. Hagen admite que a expansão de atitudes criativas capazes de inovação tecnologica será tanto mais possível quanto mais preexistirem condiçóes institucionais favorá- 
veis ao progresso técnico e um número maior de grupos venha obtendo sucesso e prestígio nas atividades técnicas. Para Lerner, - caminho para a modernização é dar condições para a expansão das personalidades empáticas: a urbanização, a alfabetização e os meios de comunicação são os processos necessários, portanto, aqui considerados mais como causas que efeitos. Mcclelland acredita que a política governamental devia aumentar as grandes unidades industriais, utilizar técnica complexa, manter a opinião pública informada, etc., para expandir as condições institucionais que criariam e incentivariam as atitudes favoráveis ao desenvolvimento. Germani concebe que a industrialização das nações desenvolvidas exige expansão geográfica, migrações e cria os meios de comunicação de massa; portanto, impede $o$ isolamento de comunidades atrasadas e expande as novas atitudes e as novas formas de vida.

A dificuldade em atribuir às atitudes tradicionais a responsabilidade do não desenvolvimento surge extremamente clara na própria análise de um teórico da modernização. Numa nação atrasada com dificuldade em se desenvolver, não prevalecem, ou sequer, existem atitudes aparentemente tradicionais. Lerner considera um dado importante da realidade a existência em nações ainda atrasadas de um grande número de transicionais, maior que o permitiriam as instituições modernas. Os transicionais seriam aquêles elementos que se caracterizam por aspirarem desenvolvimento sob a forma de valorização do modo de vida urbano, do progresso técnico, dos novos bens produzidos, das sociedades desenvolvidas e dos modelos institucionais que são os Estados Unidos, a Europa, nas áreas de educação, organização, administração, tecnologia, etc. As aspirações em têrmos de futuro mais industrializado e desenvolvido se expandem por efeito de demonstração.

Uma vez que existem aspirações e disposições favoráveis ao desenvolvimento e à mudança de modo de vida por êle exigido, parece ficar mais claro que a dificuldade de levar adiante o processo está em conseguir expandir as condições institucionais modernas para o atendimento dessas aspiraçóes e a completa modernização das atitudes. 
Lerner parece atribuir à incapacidade das elites em conduzirem o processo de modernização, desde que o confundem com poder, e não às atitudes resistentes da massa, as dificuldades do desenvolvimento.

Querer atribuir a atitudes tradicionais, quer das elites, quer das massas resistentes à modernização, as dificuldades encontradas por muitas nações em se desenvolver, parece muito distante da realidade. A política governamental, objetivando superar o atraso econômico em países subdesenvolvidos, aparece como um dado da realidade observada pelos cientistas sociais das teorias da modernização. A realidade de que tais estudiosos partem, pressupõe, portanto, um mínimo de aspiração modernizante. Os agentes sociais tentam mudar a realidade de acôrdo com um modêlo oferecido pela própria realidade, o modêlo de sociedade industrial desenvolvida. As ideologias difundidas e as políticas efetuadas pelas elites dos governos representam atitudes e comportamentos modernizadores. Nesse sentido, poderiam colocar em jôgo a própria teoria explicativa do não-desenvolvimento atribuído à falta de atitudes propícias a desencadear o processo: os elementos mais estratégicos, mais ativos envidam esforços pelo crescimento econômico.

Se admitidas as aspirações modernizantes das elites, a quem se atribuiriam as atitudes tradicionais resistentes? Alguns dos teóricos atribuem às massas e enfatizam a necessidade da política governamental criar condições para a expansão por entre as massas das características modernas. No entanto, o que dizer da existência dos transicionais apontados por Lerner? E da importância do efeito de demonstração dos padrões de vida das nações desenvolvidas através dos meios de comunicação, transportes, etc.? Germani considera que, pelo contato entre nações atrasadas e adiantadas, as populações atrasadas passam a aceitar os valôres modernos, a aspirar os mesmos bens econômicos.

Se as teorias da modernização se restringissem aos limites permitidos pela própria afirmação de que as características psicossociais criam condições e não são, de nenhum modo, conseqüêntes ou determinadas pelas condições econômico-políticas vigentes, pelas relações entre as nações, muito de suas contribujções teriam sido perdidas. Exatamente o papel do efeito-demons- 
tração, a preexistência de aspirações desenvolvimentistas, a prévalorização de valôres urbanos e industriais em comparação à efetivação de condições institucionais, estariam perdidas.

Da exposição feita, pudemos perceber como as teorias da modernização concebem os fatores causais do processo. Em resumo:

a) Características psicossociais típicas da sociedade moderna. São os fatôres causais da modernização.

b) Características psicossociais típicas da sociedade tradicional. São os fatôres responsáveis pelo subdesenvolvimento.

c) A dimensão social é explicativa da econômica.

d) Valôres sociais, atitudes e comportamentos independem da organização econômica e política. São considerados naturais a determinados povos.

e) O método científico apega-se ao senso comum na determinação das atitudes típicas de um povo responsável pelo grau de desenvolvimento.

Da exposição feita, também pudemos perceber como contradizem a tese da causalidade das características psicossociais ao enfatizarem a existência nas naçóes subdesenvolvidas de atitudes modernizantes criadas pelas instituições modernas e pelo efeitodemonstração. Em resumo:

a) As teorias da modernização invertem a relação causa-efeito. Admitem que, se as políticas governamentais desenvolverem condições institucionais e unidades industriais altamente tecnificadas, as atitudes favoráveis à modernização serão criadas, reforçadas e expandidas.

b) As teorias da modernização diminuem o poder explicativo das atitudes tradicionais face ao subdesenvolvimento: admitem a existência de elites modernizantes e, mesmo assim, as dificuldades para o desenvolvimento permanecem.

c) Admitem também atitudes e aspiraçð̃es modernizantes entre a massa. 
d) Atribuem, em grande parte, ao efeito-demonstração das naçóes desenvolvidas sôbre as subdesenvolvidas, através dos meios de comunicação, a difusão dos valôres modernos.

e) Despertam o interêsse para a expansão e difusão das aspirações modernizantes.

\subsection{O DESENVOLVIMENTO NAS NAÇOES ATRASAdAS OCORRERÃ COMO PROCESSO NATURAL DA EVOLUÇAO SOCIAL.}

Se a sociedade tradicional e a sociedade moderna são concebidas como o estado inicial e final de um processo contínuo de evolução social e os elementos impulsionadores dêsse processo são atitudes e comportamentos motivados para a realização, a mudança e a criatividade, a modernização, se não é inevitável, é plenamente possível. Os únicos obstáculos apontados são as atitudes tradicionais, contrárias à mudança. Para permanecerem rìgidamente tradicionais, os valôres em uma sociedade deveriam permanecer isolados dos outros tipos de valor. As características das nações desenvolvidas não mais permitem um isolamento completo. Ao contrário, aumentam cada vez mais os contatos.

Enquanto se utilizam de supostas atitudes tradicionais para explicar as dificuldades do desenvolvimento, os te6ricos da modernização se utilizam dos valôres modernos difundidos nas nações subdesenvolvidas através dos meios de comunicação, transportes a importaçóes de bens materiais e tecnologia para explicar que o desenvolvimento ocorrerá.

Os teóricos da modernização não estão preocupados em explicar as causas do atraso no desenvolvimento mas, em apressar o desenvolvimento. A modernização não é colocada em dúvida, mas é possível acelerar o processo. A modernização depende de determinadas atitudes favoráveis. Incentivar, reforçar, expandir tais atitudes é acelerar o processo. Simplificando, o desenvolvimento dependeria da vontade coletiva dos homens em cada nação, e seria mais fácil com a ajuda das outras nações.

Alguns dêsses teóricos não admitem a inevitabilidade da modernização, como Lerner. Para Lerner, a modernização pode ou não ocorrer segundo o tipo de govêrno. 
Hagen considera o processo inevitável. O contato das nações atrasadas com as adiantadas significou o abalo da estrutura tradicional. As elites tradicionais não perdurarão. Serão substituídas. As elites modernas, no poder, trarão o desenvolvimento.

Lerner não entende uma diferenciação tão rígida: um tipo que desenvolve e outro não. Mesmo elites que se consideram modernas ou o sejam em parte, podem não conseguir o desenvolvimento. As elites modernas podem se desviar de seus objetivos ou não perceber os elementos mais essenciais da modernização. As elites verdadeiramente modernas podem não chegar ao poder. Germani, teòricamente, não admite a inevitabilidade da modernização, mas possibilidade. Ao desenvolver sua análise, no entanto, considera que o isolamento das comunidades atrasadas não é mais possível. As sociedades tradicionais deixarão de existir, isto é, o processo é inevitável.

Inevitável ou não, a modernização é plenamente possível. Não há obstáculos intransponíveis. Seria necessário apenas que os homens estabelecessem, claramente, os objetivos desenvolvimentistas, e os meios para atingi-los.

As teorias da modernização oscilam entre atribuir inevitabilidade e um grau maior ou menor de possibilidade. A teoria clássica que atribui ao processo histórico um sentido inevitável é a teoria de Durkheim..$^{\ominus} \mathrm{E}$ a teoria de Weber que admite vários cursos possíveis conforme o sentido dado pelos agentes sociais. ${ }^{10}$ A política assume papel importante: o sentido dado à história depende da luta pelo poder entre grupos perseguindo valôres diferentes.

Os fundamentos teóricos das formulações de Durkheim e Weber se diferenciam muito mais entre si que as distinções entre as análises dos teóricos da modernização. Diante da disparidade de desenvolvimento entre as nações constatada na realidade, diante da comprovação de que há condições de um certo deDuRKHEIM, E. The Division of Labor in Society, Nova Iorque, The Free
Press, 1933.

10 Weber, Max. La Etica Protestante y el Espiritu del Capitalismo, Madri, Editorial Revista de Derecho Privado, 1955. 
senvolvimento nas nações mais atrasadas e, ao mesmo tempo, dificuldade para êsse desenvolvimento, os teóricos da modernização não se definem por essa ou aquela direção... Oscilam mesmo individualmente entre as categorias da possibilidade e da inevitabilidade. A assimilação de teorias que configuram diferentes concepções de história adveio da congruência da tipologia evolutiva de Durkheim e, da tendência geral da história onde se inserem os possiveis de Weber.

Os dois modelos de sociedade estabelecidos por Durkheim são a sociedade de pouca divisão de trabalho e "solidariedade mecânica", isto é, em que a coesão é mantida por uma consciência comum a todos, e a sociedade de intensa divisão e "solidariedade orgânica", isto é, em que a coesão é mantida pela interdependência. O $2^{\circ}$ modêlo corresponderia à sociedade contemporânea de Durkheim. As sociedades estariam orgânicamente em equilíbrio internamente e entre si. O $2^{\circ}$ tipo representaria um tipo superior de integração admitindo apenas a ação corretiva dos homens. A mudança de um tipo para o outro também não se faz pela vontade dos homens. São a concentração das populações e o aumento de intercâmbio entre os seus membros, os responsáveis pela transição. É fácil estabelecer identificações entre as teorias da modernização e Durkheim. Crescimento econômico, estrutura social flexível de acôrdo com as funções, identificada à divisão complexa de trabalho e coesão por interdependência. A sociedade tradicional, identificada à solidariedade mecânica. O princípio da evolução de um tipo simples a um complexo.

A tendência de caráter geral da historia em Weber é a racionalização crescente. A organização das sociedades se fará cada vez mais pela adequada seleção de meios para atingir fins claros e precisos. A aproximação entre Weber e Durkheim é feita através da identificação entre organização racional da sociedade e uma divisão de trabalho organizada para alcançar o fim comum. A sociedade moderna compreende uma divisão de trabalho organizada para alcançar um objetivo definido: o bem comum. De acôrdo com Weber, os homens agem para obter determinados fins, de acôrdo com Durkheim, a divisão do trabalho obtém determinados fins. Grosseiramente, nas duas coloca- 
ções, o processo histórico é voltado para um só sentido, desde que se admitam algumas variaçб̌es sem importância.

Sentidos antagônicos na história ou um mesmo processo histórico que tenha por resultante simultâneas situaçб̃es diferentes para diferentes grupos sociais, não são tedricamente nem formulados como hipótese.

A pergunta a fazer é por que não se pode conceber ou tomar por hipotese que um mesmo processo histórico foi responsável por duas resultantes em sentido oposto: o desenvolvimento e o subdesenvolvimento?

Resumindo, para as teorias da modernização:

a) O processo histórico futuro é no sentido da modernização, tal como o foi até hoje. Pelo contato com os valôres modernos, os valôres tradicionais serão superados.

b) A modernização é inevitável ou é plenamente possível. Se não ocorrer é porque os homens não a colocaram como objetivo.

c) As Teorias da Modernização oscilam entre a concepção da história de Durkheim, como evolução social linear, e a de Weber, como vários possíveis dentro da tendência de racionalização crescente.

d) Conceber o sentido da História numa mesma direção não permite pensar-se no desenvolvimento e no subdesenvolvimento como fenômenos singulares e constituídos no mesmo momento histórico.

\section{Incorporação Crítica das Teorias da Modernização numa} Compreensão Alternativa do Subdesenvolvimento.

Para as teorias da modernização, o subdesenvolvimento é identificado a um estado de origem atrasado, preexistente ao estado de desenvolvimento. A história contradiz essa tese. As atuais áreas mais desenvolvidas e mais atrasadas correspondem à diferenciação de funções nas relações entre essas mesmas áreas, estabelecidas a partir da expansão do sistema capitalista-mercantilista. A expansão mercantilista da Europa Ocidental signi- 
ficou a procura de novos mercados: mercados consumidores como alguns países orientais, e mercados supridores de produtos tropicais como algumas áreas da África, América e Ásia.

A partir do contato com as naçóes ocidentais mercantilistas, essas sociedades passaram a exercer a função de atender às necessidades comerciais das nações ocidentais. A organização social, política e econômica preexistente não é, assim, suficiente para definir as transformações conseqüentes dêsse contato. $O$ fator crucial é o tipo de contato estabelecido que vai ou não possibilitar o desenvolvimento.

Em algumas das novas áreas incorporadas ao sistema capitalista-mercantilista, a organização social, política e econômica se constituiu sem qualquer interferência das sociedades prexistentes. Na América Latina, por exemplo, as sociedades indigenas foram submetidas a um isolamento enquanto algumas foram exterminadas.

Històricamente, portanto, é insustentável a compreensão do subdesenvolvimento como um estado tradicional inerentemente atrasado, anterior ao desenvolvimento. $\mathrm{O}$ elemento definidor e histórico da constituição do subdesenvolvimento é o tipo de relações estabelecidas entre as nações mercantilistas e as áreas atingidas pela sua expansão.

Não só a constituição do subdesenvolvimento, mas o desenvolvimento do subdesenvolvimento e a sua atual situaçáo encontram suas explicações nas relações internacionais dentro do sistema capitalista mundial como posteriormente, também, as relações com o mundo socialista e no mundo socialista devem ser levadas em conta.

O nosso interêsse, porque nos toca mais de perto, está centrado nas nações subdesenvolvidas capitalistas.

São as relações internacionais, isto é, as diferentes funções que cabem a cada nação no sistema capitalista mundial, que definirão as possibilidades de desenvolvimento em cada momento histórico. 
A expansão mercantilista permitiu uma acumulação considerável de capital. A acumulação do capital em algumas naçóes possibilitou o desenvolvimento das indústrias. O capitalismo industrial não transformou substancialmente as relações internacionais. Enquanto as nações centrais se industrializavam cada vez mais, as naçóes periféricas exportadoras de produtos tropicais mais se especializavam nessa função.

A produção para exportação continuou a exercer um papel fundamental. O desenvolvimento da produção para o mercado interno dependia da expansão da produção para exportação. Sempre que os grupos exportadores aumentavam em número e em sua capacidade de consumir, a produção para o mercado interno se expandia. Ao se expandirem as atividares para o mercado externo e interno, a oferta de emprego aumentava, integrando parte da população que até então produzia apenas para a subsistência.

Com o capitalismo industrial, algum progresso técnico foi introduzido nas nações periféricas, especialmente em transportes e energia no sentido de facilitar a produção para exportação. As atividades voltadas para o mercado interno se beneficiaram dessa infra-estrutura apenas indiretamente.

Atualmente, com o capitalismo monopolista, os países desenvolvidos não só exportam produtos industriais, mas instalam grandes unidades produtivas ou participam com o capital em indústrias nacionais nas naçóes mais atrasadas. A configuração atual de muitos países da América Latina, por exemplo, apresenta um relativo desenvolvimento industrial, tanto de grupos nacionais como estrangeiros, geralmente voltados para o mercado interno e tentando exportar alguns produtos. Apresenta um setor voltado para a exportação de produtos agrícolas e matérias-primas, às vêzes semi-elaboradas. Apresenta atividades comerciais e prestação de serviços também, relativamente, desenvolvida. Apresenta grande parte da população em atividades de subsistência, em que apenas esporàdicamente a produção é exportada para um mercado próximo.

A exportação continua no seu papel de impulsionar tôdas as outras atividades econômicas. Se uma nação deixasse de obter 
capital externo, a capacidade de consumo seria extremamente reduzida. A produção para o mercado interno teria que ser reduzida, assim como parte da população empregada teria que voltar para uma economia de subsistência. As atividades de produção para o mercado externo e interno e a possibilidade de incorporar no mercado o resto da população estão estreitamente ligadas. $O$ desenvolvimento dessas nações subdesenvolvidas é possível, dentro do sistema capitalista internacional, nessa situação de complementariedade em relação às naçóes desenvolvidas. A função, o papel das nações subdesenvolvidas na divisão do trabalho internacional não depende do que elas se proponham. $O$ desenvolvimento nacional autônomo pressupóe um contrôle de tôdas as variáveis, o que e quanto produzir para o mercado interno, que tipos de técnicas utilizar, etc. $\mathrm{Na}$ função de complementariedade, o desenvolvimento auto-sustentado e autoorientado por cada nação não é mais uma possibilidade.

O limite da variabilidade de opções que podem ser feitas para o estabelecimento das políticas governamentais, está dado pela pré-definição do tipo de relaçóes internacionais mais ou menos flexíveis, nas diferentes conjunturas. As ações que desenvolvem a flexibilidade dessas relações são extremamente importantes para o desenvolvimento.

$\mathrm{Na}$ estrutura do sistema capitalista internacional e na estrutura das relações internas da população de uma nação capitalista encontram-se os fatôres objetivos no âmbito dos quais as opções humanas seriam possiveis, em têrmos de escolha de meios e de fins.

A própria percepção do mundo, da sociedade, da situação individual face aos outros, as aspiraçōes, os valôres, as motivaçőes, o modo de encarar o trabalho, o futuro, etc., advêm das relaçóes estruturais do sistema capitalista e das possibilidades que elas oferecem. Ao desenvolvimento limitado e restrito a determinadas camadas da população nos países subdesenvolvidos corresponderão capacidades de percepção, atitudes e comportamentos diferentes. Populações urbanas se diferenciarão das rurais, as que se dedicam à economia de subsistência das que se dedicam à exportação, as vinculadas às indústrias daquelas ao comércio, serviços e cargos político-administrativos, os traba- 
lhadores por conta própria dos empregados, etc. Diferenciarse-ão de acôrdo com o que recebem pelo trabalho e o que podem consumir. E evidente que se identificar valores modernos aos valôres urbanos e técnico-industriais à participação política, etc. podemos pensar em populações mais e menos modernas e atrasadas, em atitudes mais ou menos modernas. As atitudes e os valóres encontram uma explicação em situações vividas pelos agentes sociais de acôrdo com as possibilidades oferecidas pelas relações estruturais do sistema capitalista, ao nível interno da nação e ao nível das relações internacionais. Existem atitudes menos modernas, mas nem por isso elas são tradicionais decorrentes de uma organização social anterior ao aparecimento da sociedade moderna.

As atitudes mais e menos modernas assim se caracterizavam, ao mesmo tempo, durante o processo de subdesenvolvimento. As atitudes se diferenciam porque o desenvolvimento não atingiu tôdas as camadas da população. Mesmo as camadas atingidas, o foram diferencialmente.

As dimensões sociais, políticas e econômicas não podem ser isoladas numa explicação teórica que queira compreender a realidade. Na verdade, as relaçóes sociais, econômicas e políticas se estabelecem ao mesmo tempo. O modo de como os homens se organizam para produzirem juntos, define as relaçóes sociais, políticas e econômicas.

A ênfase dada à diferenciação entre atitudes modernas e tradicionais levou à preocupação pela difusão dos valôres modernos por populações ainda atrasadas. As teorias de modernização caracterizam o fenômeno do efeito demonstração. Se esclarecermos que o efeito demonstração deveria abranger tanto a valorização que existe nas nações desenvolvidas, como também a valorização das camadas sociais mais pobres face às mais ricas e das rurais face às urbanas, seria extremamente rico e mais útil face às diferentes situações das populações nas nações subdesenvolvidas.

O conceito de modernização seria extremamente útil se fôsse restrito às representaçóes e comportamentos face aos valôres culturais e materiais expandidos pelas nações em desenvolvimen- 
to. A modernização deixaria de pressupor um desenvolvimento contínuo.

A modernização entendida ao nível das representações dos agentes sociais pode antecipar ou ser posterior ao desenvolvimento, mas sempre terá, como referência fundamental, a situação vivida pelos agentes sociais e a possibilidade de mudança. Ressaltamos nessa parte:

a) O estado tradicional de origem ou não, existiu ou não, teve papel relevante na organização social, política e econômica dos atuais países subdesenvolvidos.

b) O desenvolvimento e subdesenvolvimento são processos complementares definidos pelas relações internacionais.

c) Há um limite das possibilidades de desenvolvimento dos países subdesenvolvidos de acôrdo com a divisão de trabalho internacional.

d) Nas atuais relações internacionais capitalistas não haveria possibilidade de desenvolvimento autônomo, mas sim complementar.

e) O desenvolvimento atinge de modo diferente camadas e setores de atividades.

f) Atitudes variam de acôrdo com as diferentes situações, embora num grupo possam ser valorizados modos de vida $\mathrm{e}$ bens materiais existentes apenas em outros grupos e em outras nações.

\section{Conclusão}

As teorias de modernização representam uma contribuição importante para os estudos dos valôres, representações e comportamentos dos agentes sociais em naçóes em desenvolvimento. As aspirações por um futuro mais desenvolvido é um fenômeno importante do subdesenvolvimento.

Essas atitudes não são inexplicáveis. Os valôres serão mais ou menos aceitos, de acôrdo com as situações vividas, e os compor- 
tamentos correspondentes serão mais ou menos efetivados, dependendo das condições estruturais.

As possibilidades de desenvolvimento dependem da estrutura interna de uma nação e da estrutura das relações internacionais, dentro do sistema capitalista.

Os conceitos de sociedade tradicional e moderna com referência ao âmbito nacional e os de atitudes tradicional e moderna, como responsáveis pelo desenvolvimento, não são válidos por. que não dão conta das dificuldades encontradas pelos países que querem se desenvolver. Por explicar a ocorrência de tais dificuldades reais, o conceito do sistema capitalista mundial tem validade instrumental, assim como por considerar que as atitudes e comportamentos devem ser sempre referidos, a modo de produção, às formas de organização econômica, política e social.

\section{A INTERVENÇÃO DO ESTADO NO DOMINIO ECONOMICO} Alberto Venâncio Filho

A iniciativa privada no domínio econômico adquiriu hoje importância explosiva. Êste livro analisa de maneira global - sob - ângulo jurídico, econômico e administrativo - o papel do Estado como regulador da atividade econômica, o que lhe confere caráter único de interêsse para largas faixas de público. Pedidos para Fundação Getúlio Vargas, Praia de Botafogo 188, Caixa Postal 21.120, ZC-05, Rio, GB. 